\title{
Dialogul epistolar dintre Duiliu Zamfirescu și Duiliu Ioanin
}

\author{
Drd. CIOBANU (STOICA) Ana-Maria \\ Universitatea „Dunărea de Jos” din Galați
}

\begin{abstract}
The personal correspondence of the writer Duiliu Zamfirescu is quite large and representative of the epistolary genre. It is not merely informative, it does not only contains historical data, it rises above the documentary level through literary virtues. Duiliu Zamfirescu did not think of writing literature that corresponded to his mates, but was tempted to comment on its side, to share his experience, to make appreciations, to express opinions. The daily confessions to Duiliu Ioanin sometimes take the form of diary tabs, in which we discover a young man in love. The correspondence of a writer reveals secrets he would not have wanted divulged but compose the moral and intellectual climate that conditioned the conception of the work.
\end{abstract}

Key words: epistolary genre, intellectual profile, physical portrait, artistic personality

În mod cert, Duiliu Zamfirescu nu și-a propus a face literatură corespondând cu prietenii săi, și nu numai. Ea apare din nevoia de a se confesa, de a comunica, fiind în permanență despărțit de cunoștințele, prietenii și familia sa, deoarece îndatoririle profesionale impuneau acest lucru.

În 1880, după terminarea dreptului, Duiliu Zamfirescu este numit supleant de ocol la Hârșova. Fiind izolat în micul oraș deoarece era nevoit a-și începe profesia fără prea mare tragere de inimă, tânărul Duiliu, îndrăgostit de Eliza, simte nevoia să se confeseze. Astfel, ia naștere primul capitol din bogata corespondență a autorului.

Din 1888 până în 1906 ( cu o întrerupere de doi ani ) este secretar de legație la Roma, perioadă în care va scrie operele sale principale, dar pe primul loc aflându-se corespondența, jurnalul psihologic și de creație al autorului, ce conține pagini întregi de călătorii și memorialistică. În Italia i se schimbă viața. Vizitează bineînțeles Roma, apoi Neapole, Florența și Veneția, începe să studieze istoria și arheologia alcătuindu-și o adevărată bibliotecă de specialitate. La Roma diplomatul intră în cercurile mondene, pe care, cel puțin la început, le privește cu superioritatea celui ridicat prin forțele proprii. În 1890 se căsătorește cu Henritte Allievi, fiică de senator. Va duce o viață bună , cu plimbări la Anzio, Amalfi sau în apropierea Romei. Deși călătorea mereu prin Europa, Duiliu Zamfirescu s-a simțit singur și izolat de viața literară din patrie, de prieteni, de 
familie, iar dorul de apropiați a intensificat necesitatea de a comunica și cum altfel decât prin scrisori. Atunci când scrie, se regăsește pe sine, se pune în legătură cu pământul natal și cu prietenii, ce se află în permanență în gândurile lui chiar dacă e la Roma , Atena sau Bruxelles, iese din singurătate, se apropie de țară și de cei dragi. Corespondența din această perioadă ne dezvăluie un iubitor de artă și arheologie, un călător pasionat, descriind toate locurile îndrăgite ale sudului în scrisorile sale, definindu-l pe diplomatul, pe scriitorul și omul de lume, Duiliu Zamfirescu. În perioada cât a stat la Roma , Duiliu Zamfirescu s-a dezăluit în scrisori sub toate aspectele, transmițându-și gânduile și impresiile, descriind, teoretizând, autocriticându-se și confesându-se.

Revenind în țară,în 1906 e numit secretar general al Ministerului Afacerilor Străine, iar în 1909, reprezentantul României la Comisia Europeană a Dunării, cu grad de ministru plenipotențiar. Odată cu stabilirea permanentă în țară, scrisorile se împuținează și se oficializează, nu mai au semnificații deosebite, în afara acelora strict istorico-literare.

Astfel, Alexandru Săndulescu realizează o clasificare cronologică a corespondenței destul de numeroasă a lui Duiliu Zamfirescu astfel:

1. Până la plecarea lui Duiliu Zamfirescu în Italia( 1876 -de când datează prima scrisoare-1888)

2. Perioada Roma ( 1888- 1906) incluzând și cei doi ani (1892-1894) când a fost transferat la Atena și Bruxelles

3. Stabilirea în țară după 1906.

Corespondența cea mai importantă din prima perioadă este cea trimisă prietenului Duiuliu Ioanin, o corespondență de 39 de scrisori.Îl cunoaștem pe tânărul Duiliu Zamfirescu, care, student fiind, îți petrecea vacanța la moșiile arendate de părinți prin județele Brăila și Râmnicu Sărat sau la via de la Vârteșcoi , în apropierea Focșanilor, bucurându-se de soare, hoinărind prin păduri la vânat. Poeziile și nuvelele de debut sunt inspirate din aceste experiențe. "Am putea spune că aceasta e perioada când epistolierul „îți face mâna" ( de altfel ca și poet și prozatorul) când profilul său moral abia începe să se contureze."129 Prin paginile scrisorilor adresate prietenului din copilărie, Duiliu Ioanin, îl cunoaștem pe tânărul student ce-și petrece vacanța la moșiile arendate de părinți prin județele Brăila și Râmnicu Sărat, sau la via de la Vârteșcoi, în apropierea Focșanilor, bucurându-se de soarele blând, hoinărind prin păduri.

${ }_{129}$ Duiliu Zamfirescu, Cele mai frumoase scrisori, Editura Minerva, București, 1974, pag VII. 
În prezenta lucrare, am urmărit, în urma analizei scrisorilor lui Duiliu Zamfirescu către prietenul din tinerețe, Duiliu Ioanin, utilizarea descrierii, ca mod de expunere predominant, portretizarea, conturarea trăsăturilor de caracter ale tânărului scriitor.

\section{Utilizarea descrierii ca mod de expunere predominant}

Duiliu Zamfirescu folesește descrierea în corespondență pentru o relatare cât mai exactă a locurilor, pentru o informare cât mai clară a celui cu care poartă dialogul epistolar. Și acest lucru se întâmplă încă de la început, aproape de la primele scrisori. Putem observa asta și în scrisorile adresate lui Duiliu Ioanin. Aflat la Focșani, merge la o partidă de vânătoare și descrie prietenului său pădurea.,, Am fost zilele trecute la vânat. Zău, nu știi ce farmec deosebit are liniștea pădurii, ce șoaptă lungă s-aude în căderea fiecărei frunze și ce mărturie tristă, găsești la fiecare pas, sub picioare, despre destinata lucrurilor pe pământ.Și iarăși, când bate vântul, ce zgomot asurzitor, câte glasuri multiple ies din îmbătrânitele piepturi ale plopilor uriași."130 $\mathrm{Nu}$ doar pădurii acordă atenție descriind-o, ci și gârlei, care trece prin mijlocul ei, despre care aflăm din scrisoare că se chiamă Râmna. "Prin mijlocul pădurii trece Râmna, o gârlă frumoasă, pe a cărui prund am stat cu pușca-n mână câtăva vreme, uitându-mă cum curgea apa încet ... încet."131

Fiind numit supleant de ocol la Hârșova, este nevoit să se mute acolo. Nu pierde ocazia de a-i descrie prietenului său localitatea unde s-a instalat. ", Hârșova e frumoasă dar e tristă: zidur de stânci la poalele cărora apa sună monotonul cântec al călătoriei, ruine prin ferestrele cărora vântul și singurătatea se sărută ca doi amanți; bărci cu pânze albe , veseli fluturi ai Dunării și pescari, păsări de apă ce trec țipând pe deasupra noastră, toate acestea sunt frumoase, dar sunt triste și de tristețe aș vrea să fug. În mine am destulă. Aici egoismul de a vedea natura formând o oglindă a sufletului nu-1 mai am deloc."132

Meseria sa necesită deplasări pentru anchete prin satele dobrogene și printre munți. Este impresionat și de Munții Măcinului, pe care-i cutreieră pentru a junge la diferite destinații , atunci când este nevoie , $\mathrm{Nu}$ știu pentru ce acești munți au ceva misterios într-înșii, măreț, impunător. Este o vegetație cenușie și peste tot bogată, care-ți înfățișează tabloul unui deșert. La rari

\footnotetext{
${ }^{130}$ Duiliu Zamfirescu, Opere, Vol VII, Editura Minerva , București, 1984, pag.103.

${ }^{131}$ Ibidem.

132 Ibidem, pag. 104.
} 
intervale se zăresc cășerii mocănești, cu turme de oi, imense, formând niște adevărate oaze în mijlocul singurătății."133

Descriere ce stârnește râsul, descoperim în scrisori, atunci când prezentă casa notarului de la Ostrovu - „un sat rătăcit din văile Balcanilor", trimis acolo pentru a constata o crimă: „O casă de notar este tot ce-a lăsat Dumnezeu mai desperecheat. Dacă-ți dă papuci, are numai unul, dacă-ți dă tacâmuri, are numai furculiță, dacă te poftește să faci țigară, are tutun și n-are hârtie, în sfârșit, notar, notar, în toată puterea cuvântului."

Numit procuror la Tribunalul Dâmbovița (Târgoviște), este nevoit să părăsească meleagurile Dobrogei pentru a începe o viață nouă aici, unde stă cu gazdă. Și de aici îi scrie prietenului său, povestindu-i nu doar despre gazda sa, potretizând-o, ci și despre împrejurimile orașului unde s-a mutat, mai exact Mănăstirea Dealului, o descriere poetică am putea spune, memorabilă. „Pozițiile din prejurul Târgoviștei sunt în adevăr admirabile. În momentul în care-ți scriu, trompetele de la Mănăstirea Dealului cântă ceasurile de culcare, și accentele lor dulci și depărtate parcă invită somnul să ne adoarmă. Cântecul zorilor seamănă cu glasul uitării; de aceea îți dișteaptă în suflet o tristețe inexplicabilă, un regret dulce, o simţire poetică, care moare cu tăcerea lor. Trebuie să știi că la Mănăstirea Dealului astăzi nu mai sunt decât vreo patru călugări, ultimele rămășițe ale unei generații care a cunoscut pe Cârlova tânăr; ceilalți au murit, iar lăcașul cel sfânt azi e cazarmă pentru școala divizionară. Mai jos e Mănăstirea Viforâta, unde se zice că ar fi iubit Cârlova pe maica Elisabeta, pe iubita lui Lina. Această mănăstire e încă locuită de maici, și încă bine locuită, căci are vreo 80 de călugărițe. Cât oi putea de curând o să mă duc să le vizitez.

Îți închipuiești tu un amor într-o mănăstire? Trebuie să fie așa de sfânt și așa de dulce !..... A !....tu ți-l închipuiești fiindcă tu ai iubit într-o mănăstire."134

\section{Portretizarea ca mijloc de imortalizare și transmitere de informație}

Ajuns în satul Topolog tot datorită îndatoririlor profesionale, întâlnește un turc ce l-a impresionat, povestindu-i și prienenului său atât despre dânsul cât și despre familia lui. „, La Topolog am găsit un turc cu multă omenie, pe care-1 avusesem la instrucție și care se chema Sadîc. M-a cinstit, m-a sărbătorit, mi-a povestit de la socru lui Mahomed. E singurul turc pe care l-am auzit vorbind de femeia sa, sau mai bine zicând de femeile sale, căci are două. Se plânge sărmanu

${ }^{133}$ Duiliu Zamfirescu, Opere, Vol VII, Editura Minerva , București, 1984, pag.118.

${ }^{134}$ Ibidem, pag. 138. 
că n-are copii; deci înțelegi pe ce gamă se aranja destăinuirea lui, mai ales că era și doctoru de față."135 Nu doar turcul l-a impresionat pe Duiliu Zamfirescu ci și modul de viață al femeilor turce. ", Intr-adevăr , când te gândești la degradarea intelectuală în care e ținută femeia turcă , te revolți contra tuturor legilor lor, și-ți vine să zvârli cu fesu după Mahomed. Atâta egoism nu s-a mai văzut la nici un profet pământean! Femeile sunt niște adevărate mașini de copii, niște râșnițe, care îndată ce se hodorogesc puțin trece în camera vechiturilo."136 O astfel de întâmplae stă la baza nuvelei Noapte bună.

Deasemeni ține să-l informeze pe Duiliu Ioanin despre prietenul său cu care locuiește, despre cel care ajunge a-i fi confesor. „, Am un prieten de 70 de ani, doctor. Dacă poartă părul etății lui pe frunte, în piept poartă o inimă ca a noastră, tânără, entuziastă, bună. E polonez și prin urmare e republican .Locuiesc cu dânsul. Visând și discutând împreună despre libertate, despre fericire, despre Dumnezeu, am ajuns fără voie să-i spui aceea ce aveam prea mult în inimă : iubirea mea."137 Iată că nu se confesează doar prin scrisori ci-și face prieteni față de care își deschide sufletul.

Proaspăt mutat la Târgoviște unde este numit procuror în 1881 își ia gazdă la Marița Sardareasa cu care stabilește repede o relație frumoasă, bazată pe respect. „,Acum mă găsesc cu domiciliul la cucoana Marița Sardareasă, un fel de smochină omenească cu colţi pe frunte, care la fiecare vorbă te drăgostește ; maică-n sus, maică-n jos, domnule procuror mamă, la dreapta, băiatu mami la stânga; în sfârșit un putinei de bunătăți."138

\section{Conturarea trăsăturilor de caracter ale tânărului Duiliu Zamfirescu}

„Cea mai durabilă și cea mai actuală operă a lui Duiliu Zamfirescu este corespondența lui literară. Nicăieri nu s-a exprimat scriitorul mai original, mai spontan și mai viu ca în sutele de epistole trimise de-a lungul anilor din peregrinajul său diplomatic. El și-a construit involuntar un autoportret moral, care trebuie în sfârșit confruntat cu acela contrafăcut în bună măsură de contemporani și a risipit veritabile pagini de literatură, născute dintr-un condei înzestrat, alunecând nestingherit de prejudecăți pe hârtie. "139

\footnotetext{
135 Ibidem, pag. 119.

136 Ibidem.

137 Ibidem, pag.126.

138 Ibidem, pag.137.

139 *** Biblioteca critică, Duiliu Zamfirescu , Editura Eminescu, București, 1976, pag.294
} 
Aflat la Focșani, merge la o partită de vânătoare,descrie pădurea , atras de liniștea acesteia. Acest lucru denotă sensibilitatea poetului, înclinația lui pentru liniște și singurătate. Sigur că între paginille acestor scrisori aflăm pe Duiliu Zamfirescu este îndrăgostit de Eliza Ioanid căsătorită Dănescu. O iubire sinceră, așa cum ne putem da seama, deoarece el îi dorește doar bine chiar dacă ea se va căsători cu altul.

„Şi apoi, când visurile vor trece, când din femeia nobilă și ideală a tinereții va rămâne numai femeia onestă a maturității, poate va fi pe deplin fericită.

Vezi tu, această idee de o fericire posibilă mă indignează; și cu toate astea i-o doresc din suflet, din adâncul inimii."140

O iubește atât de mult încât găsește asemănări și trăsături de-ale Elizei și în alte fete pe care le cunoaște întâmplător. „, Să-ți spun ceva: este aici o fetiță a unui bătrân foarte de cinste, fratele profesorului Circă; am găsit oarecare asemănare în voiciunea și umbletul ei cu acela al Elizei. Când ai ști cum mi-a bătut inima văzând-o de departe !... Păcat că nasul îl are în miniatură numai."141 Nu doar că este îndrăgostit dar și suferința sa datorită acestei iubiri irealizabile transformă scrisorile către prietenul său în adevărate file de jurnal.

Fire sensibilă, realist - după cum se poate observa , Duiliu Zamfirescu detestă noua meserie , mai ales aspectele sale urâte, dându-și seama singur, că nu este făcut pentru meseria de procuror. „Dacă ai sta ca mine toată ziua să primești la plângeri și să asculți pe toți nebunii spunând de când a urzit Dumnezeu pământu; dacă ai fi silit să-ți petreci cea mai mare parte din vreme afundat cu nasu și cu spiritu în dosare, ai înțelege ușor cu câtă bucurie primesc scrisorile tale și cu câtă nerăbdare le citesc. Hotărâtor, nu sunt făcut să fiu procuror."142 Este cunoscut faptul că Duiliu Zamfirescu provine dintr-o familie modestă. Dar acest lucru nu-l împiedică să-și dorească celebritatea. Astfel încetul cu încetul ambiția, dorința de a deveni cunoscut pun stăpânire pe tânărul poet.,,Iți mărturisesc că am momente de furioasă dorinţă de a deveni celebru. Ele trec însă ca niște gânduri străine îndată ce-mi aduc aminte de tristul glas al inimei mele."143

Nu doar că este sensibil, realist, inteligent, dar Duiliu Zamfirescu are și simțul umorului. Îi descrie prietenului său momentul în care traversează Dunărea alături de un curcan într-un mod haios care fură cu siguranță zâmbete

\footnotetext{
${ }^{140}$ Duiliu Zamfirescu, Opere, Vol VII, Editura Minerva , București, 1984, pag.108.

${ }^{141}$ Ibidem, pag. 111.

142 Ibidem, pag. 107.

143 Ibidem, pag. 117
} 
celor ce lecturează această corespondență. ," Alături de mine era un curcan pe care-l aduceam de la țară și care nu-nțelegea deloc ce însemna acel zgomot drăcesc de apă și acea legănare fără sfârșit. Într-un moment, un val răsfrânt de maluri 1-a făcut să înțeleagă, printr-o dușe foarte demonstartivă, natura zgomotului. Să fi văzut de-acolo protestații pe bietu curcan. ${ }^{144}$

Preferințele sale literare, dorința de afirmare, colaborarea cu diferite periodice nu fac decât să ne prezinte pe tânărul Duiliu Zamfirescu preocupat de literatură, de frumos. Ba chiar are cunoștințe literare suficiente pentru a-1 introduce și pe Duiliu Ioanin în universul operei pe care-l studiază. ," Nu știu dacă cunoști opera lui Castelar : Amintiri de Italia. E în adevăr cea mai splendită creație a secolului nostru, o operă titană, vie; un gigant care trăiește din oasele cimitirelor, din ruinele monumentelor, din viața trecutului, dar un gigant atât de gigantic, atât de mare, încât, în adevăr, ești mândru gândindu-te că creierul omenesc în al XIX-lea secol poate să producă astfel de colosale lucruri."145

Ne dăm seama de inteligența scriitorului , de cunoștințele sale literare ce par a fi destul de vaste și de preocuparea pentru scris nu doar din lectura sa ci și din traducerile pe care le realizează, anume drama Hernani, scrisă de Victor Hugo, traduceri pe care le realizează cu plăcere. „Cred să-ncep actul III din Hernani cu o ardoare tot atât de mare ca mai nainte." 146 Citește pe Rousseau și pe Lamartine, pe Musset dar și pe Emilio Castelar, despre a cărui carte - L'art, la religion et la nature en Italie ( pe care o numește Amintiri în Italia) care-i place nespus de mult și despre care are doar cuvinte de laudă. „, Nu știu dacă cunoști opera lui Castelar: Amintiri de Italia. E în adevăr cea mai splendidă creație a secolului nostru, o operă titană, vie; un gigant care trăiește din oasele cimitirelor, din ruinele monumentelor, din viața trecutului, dar un gigant atât de gigantic, atât de mare, încât, în adevăr, ești mândru gândindu-te că creierul omenesc în al XIX-lea secol poate să producă astfel de colosale lucruri. E credința brahmanilor asupra nemurirei sufletului, unită cu cugetarea lui Platon și elocința frazei lui Bossuet; este poezia lui Lamartine scrisă pe lespezile înnegrite ale Colliseului; este melancolia exilului șoptită visătoarei Veneții și nălucirelor mării; este, în sfârșit cea mai mare și cea mai frumoasă poemă care s-a scris vreodată în proză."147

${ }^{144}$ Ibidem, pag. 135.

145 Ibidem, pag. 100.

${ }^{146}$ Ibidem, pag.117.

${ }^{147}$ Ibidem, pag. 100. 
Preocupările sale literare nu se rezumă doar la traduceri și lecturi ci , așa cum aflăm din scrisori ci scrie și publică. În România liberă, apare în decembrie 1880 nuvela O pagină din viața lui Strauss, dedicată „Doamnei E. D", adică Elizei, nuvelă despre care dorește să afle părerea prietenului său. „, Ai cetit nuvela mea din România liberă? Spune-mi în scrisoarea viitoare câte lucruri nu ți-au plăcut și ce ți-a plăcut."148 Și nu doar nuvele , schițe și portrete publică. Îndrăgostit și trist compune poezii pe care le publică sau le trimite prietenului cu rugămintea de a le publica. ", În tristețea care m-a coprins întorcându-mă acasă, am scris această mică poezie, atins de poetica frumusețe a unui biet trandafir pe care mama mi l-a adus dintr-o glastră. Fii bun și treci pe la Literatoru spre a o lăsa să se publice."149 Este vorba despre poezia Un trandafir, publicată în Literatorul în anul 1881.

„Corespondența lui Duiliu Zamfirescu constituie un gen literar; dincolo de document ea se impune și prin însușiri stilistice, prin investigație psihologică, prin bogăție de senzații, dacă nu și de idei. A compune o scrisoare cu frumuseți literare, la capătul unei sforțări, cade în putința oricărui scriitor. Arta epistolară nu constă într-un efort, ci în capacitatea de a produce involuntar, cu necesitatea indiferentă a bradului ce dă răşină, alimentată de o sevă continuă și fatală; ea e efectul unei stări sufletești ce reclamă nevoia comunicării directe, a unor senzații, a unor impresii." 150

148 Ibidem, pag.133.

149 Ibidem, pag.141.

150 E. Lovinescu, T. Maiorescu și posteritatea lui critică, Ed. Casa Școalelor, București, 1943, p. 116. 


\section{Bibliografie:}

Bucuța Emanoil, Duiliu Zamfirescu și Titu Maiorescu în scrisori, Fundația pentru literatură și carte „,Regele Carol", București, 1937

Cioculescu Șerban, Istoria literaturii române III, Epoca Marilor Clasici, Editura Academiei Republicii Socialiste România, București, 1973

Cioculescu Șerban, „O față nouă a lui Duiliu Zamfirescu”, revista Fundațiilor Regale, Anul III, 1 aug. 1936, nr.8

Săndulescu Alexandru, Literatura epistolară, Editura Minerva, București, 1972

Lovinescu Eugen, T. Maiorescu și posteritatea lui critică, Ed. Casa Școalelo, București, 1943

Săndulescu Alexandru, Duiliu Zamfirescu. Scrisori inedite, Editura Academiei Republicii Socialiste România, București, 1967

Săndulescu Alexandru, Duiliu Zamfirescu. Cele Mai frumoase scrisori, Editura Minerva, București, 1974

Săndulescu Alexandru, Duiliu Zamfirescu și marele său roman epistolar, Editura Minerva, București, 1986

Zamfirescu Duiliu, Opere, Vol VII, Editura Minerva , București, 1984

Biblioteca critică, Duiliu Zamfirescu , Editura Eminescu, București, 1976 